\title{
Community Involvement in Community Health Need Assessment
}

\author{
Naveen Shrestha ${ }^{1^{*}}$ \\ ${ }^{1}$ Public Health Department, Central Institute of Science and Technology College, New Baneshwor, \\ Kathmandu, Nepal.
}

Various community health programs planned either by governmental or non-governmental sectors have not achieved the goals because most of them are the topdown fashion. Assorted health connoisseur pinpoints the health needs of the community, in fact the health needs of the community are not perceived yet by the community people as such. Therefore, there is continually a big pause between observed need and felt need. Here observed needs imply those needs, which are identified by the health experts, using distinct modes to obtain the information. On the other hand, felt needs are those needs, which are actually perceived by the community people. Both are not the real needs of the community. It is usually differ in both needs, if coincidentally matched then the needs are the real needs of the community and program will meet the goals. So that we can say that, the real need is the compromise between observed and felt need (Fig. 1). If we designed health service program based on real need of the community then the success of program is in no doubt

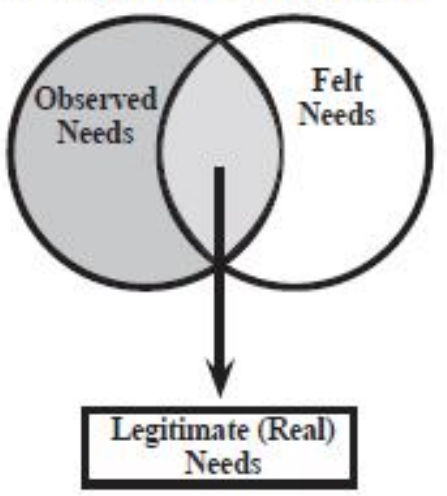

Fig. 1: Relationship of different needs

This indicates the involvement of community people is crucial for health need assessment. The question insurrected how could we involved the community people in this exercise. It is very difficult to involve all the community people in whole process so carefully selected people in different processes of need assessment could be beneficial for program.

Health need assessment is the systematic approach to identify the community health problems by using the community people. It involves epidemiological, qualitative, and comparative methods to describe health problems of a community identity; inequalities in health services and determines priorities for the most effective use of resources.

Community people can be utilized in different stages of community health need assessment as described in figure 2 .

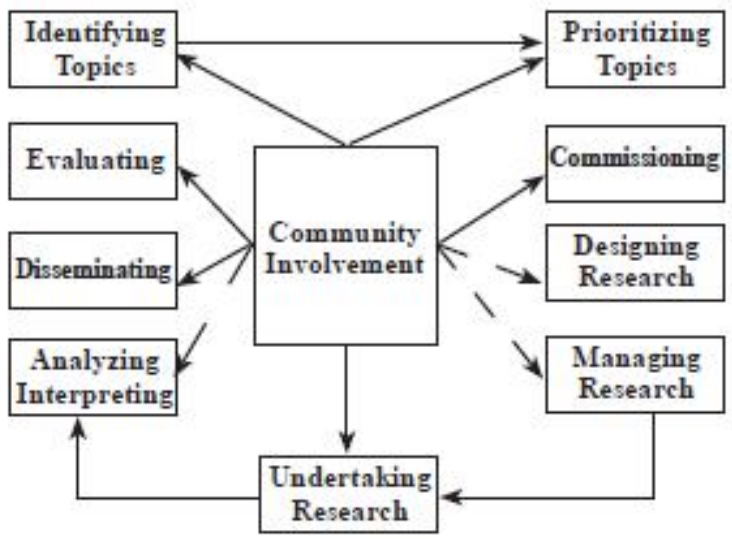

Fig. 2: Community involvement in research process

Community involvement in health need assessment increases the ownership towards the program. One executive committee has to be formed consisting of researchers and selected community representatives from the two deprived wards who are well recognized as well as technically some how well. Researchers and participating community members should negotiate on following points:

Research goals and objectives

Methods and duration of the project

\footnotetext{
Correspondence: Prof. Naveen Shrestha, Public Health Department, Central Institute of Science and Technology College, New Baneshwor, Kathmandu, Nepal.
} 
Shrestha N, Community Involvement in Community Health Need Assessment. JHAS 2010; Vol. 1, No. 1, p. 60-61

Terms of the community-researcher partnership

Degree and types of confidentiality

Strategy and content of the evaluation

Place where data to be stored, current interpretation of data, and future control and use of data and human biological material

Methods of resolving disagreements with the collaborators

Incorporation of new collaborators into the research team

Joint dissemination of results in lay and scientific terms to communities, clinicians, administrators, scientists, and funding agencies

After negotiating on previously mentioned points the committee members are more or less responsible for conducting all the stages of community need assessment. Now I would like to explain how we could involve the community people in every step of need assessment:

1. Identifying topics: Group discussion should be conducted with community people to identify the topics using available all secondary data eg demographic information, activity data, health and social care surveys and ad hoc studies of service quality. The researchers should help the community people providing data and interpreting the data and community people ultimately identify the number of topics from available data.

2. Prioritizing: If the committee members identify the number of topics then it is not possible to conduct programs on those topics due to limited resources. Therefore, prioritizing the topics among those topics where resources are available is necessary. Committee members will prioritize on the basis of following points:

Magnitude of problems

Problems matching with national health policy

Match with community desire

Effective and appropriate solutions

Resource (Man, Money and Materials) available

3. Commissioning: Community people also involved during the commissioning process that increase the ownership of program.

4. Designing research: This part is very technical so that community people can be involved partially to design the research. If there is some one who is very sound in research can be involved otherwise not in this process. Further information needed on prioritized topic can be obtained by using rapid appraisal method. Rapid appraisal can be used to involve the community in the identification of local health needs and can supplement other more formal methods of assessing needs. Rapid appraisal is best used in homogeneous communities like deprived communities. Data are generally collected from three sources:

Interview with key informants from both wards

Some Focus Group Discussions (FGDs) with selected groups

Observations made in the homes of key informants

Interview schedule, FGD guideline and observation checklist should be developed in consultation with different health experts within the research team and all tools will be modified and finalized after field test.

5. Managing research: This is also more technical part so only partial involvement can be possible.

6. Undertaking research: During this phase, maximum community people beyond the committee members must be utilized to collect the required information. Prior to the data collection separate training programs will be organized to conduct interview and FGDs. Both theoretical as well as practical session are needed to collect exact information. Involvement of community people in this phase helps community in many ways:

Capacity building within the community

Increase the ownership towards the program

Income generate within the community

Perceive their needs themselves

7. Analyzing and interpreting: Analysis is very technical part and if some committee member from community has skill on analysis then he can be involved in this process otherwise not. But in interpreting the result, community people can be utilized by guiding them to interpret.

8. Disseminating: Joint dissemination of results in lay and scientific terms to communities, clinicians, administrators, scientists, and funding agencies should be organized.

9. Evaluating: community people also can be used in evaluation program.

In this way community involvement in health need assessment help to identify the legitimate community health needs. 